Research Article

\title{
Mechanical Properties of Polypropylene Macrofiber-Reinforced Concrete
}

\author{
Zhishu Yao $\mathbb{D}^{1},{ }^{1}$ Xiang Li $\mathbb{D}^{1},{ }^{1}$ Cao Fu, ${ }^{1}$ and Weipei Xue $\mathbb{D}^{1,2,3}$ \\ ${ }^{1}$ School of Civil Engineering and Architecture, Anhui University of Science and Technology, Huainan 232001, China \\ ${ }^{2}$ Post-doctoral Research Station of Safety Science and Engineering, Anhui University of Science and Technology, \\ Huainan 232001, China \\ ${ }^{3}$ Safety Science and Engineering Postdoctoral Research Workstation, China Coal Mine Construction Group Co. Ltd., \\ Hefei 230000, China
}

Correspondence should be addressed to Xiang Li; lixiang6897@126.com

Received 2 February 2019; Revised 11 April 2019; Accepted 17 April 2019; Published 7 May 2019

Guest Editor: Kazunori Fujikake

Copyright (c) 2019 Zhishu Yao et al. This is an open access article distributed under the Creative Commons Attribution License, which permits unrestricted use, distribution, and reproduction in any medium, provided the original work is properly cited.

To economically and reasonably solve the difficult problem of mine shaft support subject to complex geological conditions, we studied the mechanical properties of polypropylene macrofiber-reinforced concrete (PPMFRC). First, we selected test raw materials through an investigation and comparison of technical parameters. Second, using a preparation test, we obtained the composition of reference concrete of PPMFRC for the mine shaft lining structure, and test specimens were manufactured according to relevant test technical regulations. Finally, the mechanical properties of the specimens were compared, and the results show that the compressive, flexural, and tensile strengths of PPMFRC were increased by approximately $3 \%, 30 \%$, and $20 \%$, respectively, for mixtures with polypropylene macrofibers. The fracture toughness of PPMFRC was between 0.26 and 0.35 , and the fracture energy was between $382.7 \mathrm{~N} / \mathrm{m}$ and $485.6 \mathrm{~N} / \mathrm{m}$, which is significantly higher than that of plain concrete. The test results show that PPMFRC is an ideal material for the lining structure of a mine shaft under complex geological conditions, and we have provided technical parameters for engineering applications.

\section{Introduction}

To exploit deep underground mineral resources, vertical shafts must be constructed in the stratum to transport minerals, personnel, materials, equipment, ventilation, etc. A wellbore maintains stability because of a shaft lining structure close to its inner wall. In the past, plain concrete was primarily used for the lining. However, with the increase of mining depth, the engineering geological and hydrological conditions of the strata through which the wellbore passed became more complex. Meanwhile, the concrete used in the shaft lining was subjected to compressive stress, tensile stress, etc. Hence, the concrete cracked easily. Further, when subjected to underground pressure water, the cracks caused fracture and expansion, which seriously affected the safe use of the shaft. Thus, concrete for deep shaft lining required not only high compressive strength, but also high tensile strength, flexural strength, crack resistance, and permeability resistance. A few scholars developed shaft lining structures made of steel fiber and steel skeleton-reinforced concrete, and these new types of reinforced concrete were successfully applied to engineering practices [1-4]. Nevertheless, through engineering applications, they were considered expensive and easily corroded. Therefore, it is necessary to find a new material for the shaft lining structure.

Polypropylene macrofiber is a fiber with diameter and length exceeding 0.1 and $40 \mathrm{~mm}$, respectively, and it is developed from polypropylene and polyethylene, which are the main raw materials. When the polypropylene macrofibers in concrete reach a certain level, they behave in a manner similar to steel fibers. Thus, the fibers are also referred to as "imitation steel fibers" [5-7]. Polypropylene macrofibers have many advantages such as high tensile strength, corrosion resistance, good chemical stability, strong bonding strength with concrete, and easy construction. However, few researchers have investigated the 
application of polypropylene macrofiber-reinforced concrete (PPMFRC) to underground structures. To economically and feasibly solve the difficult supporting problems of mine shaft lining structures under complex conditions, PPMFRC was prepared and its mechanical properties were studied.

\section{Materials and Preparation}

\subsection{Materials}

2.1.1. Cement. In this study, Conch P.II 52.5 Portland cement, with the specific surface area $389 \mathrm{~m}^{2} / \mathrm{kg}$, was selected. Its initial and final setting times were 145 and $199 \mathrm{~min}$, respectively, and the cement was qualified as stable. Its $3 \mathrm{~d}$ compressive and flexural strengths were 25.7 and $4.6 \mathrm{MPa}$, respectively, and its $28 \mathrm{~d}$ compressive strength and flexural strength were 55.8 and $7.3 \mathrm{MPa}$, respectively.

2.1.2. Aggregate. Sand from Huaihe River was selected as the fine aggregate with a fineness module of 2.9 and saturated surface drying density of $2580 \mathrm{~kg} / \mathrm{m}^{3}$. Basalt gravel was selected as the coarse aggregate with a particle size of less than $25 \mathrm{~mm}$ and saturated surface drying density of $2720 \mathrm{~kg} / \mathrm{m}^{3}$.

2.1.3. Plasticizer. This study used the high-performance water-reducing agent NF produced by Anhui Huaihe Chemical Co., Ltd.; its water reducing rate is greater than $30 \%$.

2.1.4. Admixture. Furthermore, this study used slag, with a specific surface area greater than $350 \mathrm{~m}^{2} / \mathrm{kg}$, produced by Anhui Hefei Qingya Building Material Co., Ltd. The microsilicon powder produced by Shanxi Dongyi Ferroalloy Factory was selected. Its specific surface area was greater than $18000 \mathrm{~m}^{2} / \mathrm{kg}$.

2.1.5. Fiber. The polypropylene macrofiber produced by Hangzhou Jianqing Fiber Company was selected (Figure 1). The parameters of the fiber are listed in Table 1.

2.2. Mixture Composition and Preparation. Existing studies have generally used concrete with a standard cubic compressive strength of $60 \mathrm{MPa}$ (C60) for shaft lining structures, and thus, C60 was taken as the design value of concrete strength in this test. The composition of the reference concrete for the test was then obtained from an orthogonal test (Table 2).

Four groups of specimens were needed for each test. One group comprised plain concrete specimens; these were considered to be reference concrete. The other three groups were PPMFRC specimens containing 0.5\%, 1.0\%, and $1.5 \%$ (volume fraction) fibers. The four groups were named A- 0 , A-0.5, A-1.0, and A-1.5, respectively. Each group had three specimens whose shapes and sizes corresponding to each test are shown in Figure 2.

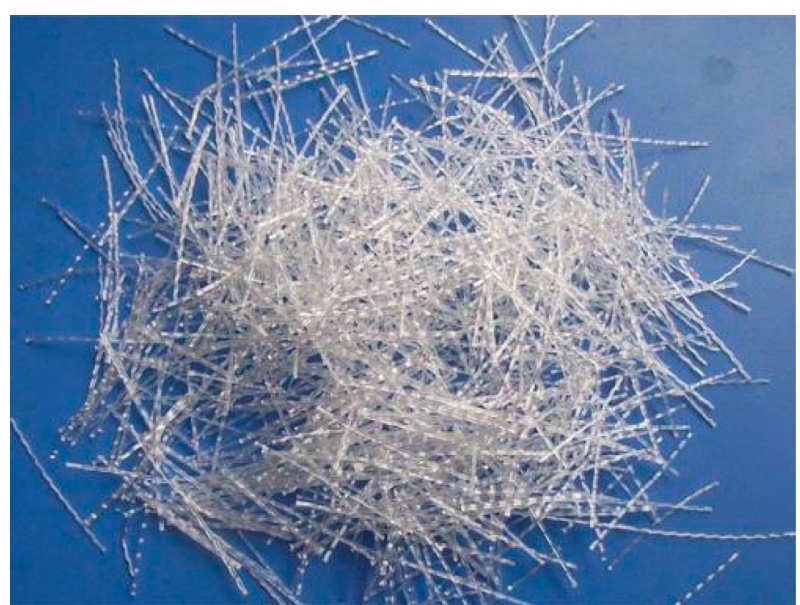

Figure 1: Polypropylene macrofibers.

TABLE 1: Characteristic parameters of polypropylene macrofiber.

\begin{tabular}{lcccc}
\hline $\begin{array}{l}\text { Length } \\
(\mathrm{mm})\end{array}$ & $\begin{array}{c}\text { Equivalent } \\
\text { diameter } \\
(\mathrm{mm})\end{array}$ & $\begin{array}{c}\text { Length- } \\
\text { diameter } \\
\text { ratio }\end{array}$ & $\begin{array}{c}\text { Density } \\
\left(\mathrm{kg} / \mathrm{m}^{3}\right)\end{array}$ & $\begin{array}{c}\text { Tensile } \\
\text { strength } \\
(\mathrm{MPa})\end{array}$ \\
\hline 55 & 0.85 & $\geq 65$ & 0.91 & $\geq 450$ \\
\hline
\end{tabular}

TABle 2: Composition of reference concrete $\left(\mathrm{kg} \cdot \mathrm{m}^{-3}\right)$.

\begin{tabular}{lcccccc}
\hline Cement & Sand & Gravel & Water & Admixture & Slag & Silica fume \\
\hline 400 & 667.2 & 1088.5 & 164.3 & 7.2 & 105 & 25 \\
\hline
\end{tabular}

The sequence for mixing the PPMFRC was as follows. First, cement, aggregate, and admixture were dry-mixed in a concrete mixer for $2 \mathrm{~min}$. Second, polypropylene macrofibers were added and the mixture was stirred for $2 \mathrm{~min}$. Then, NF water reducer was dissolved in $60 \%$ water and poured into the mixer for $3 \mathrm{~min}$. Finally, the remaining $40 \%$ of the water was poured into the mixer and stirred for $3 \mathrm{~min}$.

Specimens were poured and vibrated onanHZJ-0.8 concrete shaking table until slurry was discharged. After shaping, the surface was immediately covered with impervious film and the specimens in molds were placed in an ambient temperature of $20^{\circ} \mathrm{C}$ for $24 \mathrm{~h}$. Then, the specimens were demolded and placed in a YH- 40 standard curing box $\left(20 \pm 2^{\circ} \mathrm{C}, 95 \% \mathrm{hu}-\right.$ midity) for $28 \mathrm{~d}$.

2.3. Experimental Methods and Facilities. In the experiment, the WAW2000B universal testing machine developed by SFMIT was used, and the load and displacement were recorded using the Test Master software [8,9]. After all specimens were removed from the standard maintenance box, they were wiped clean with a dry cloth, and then they were placed in the dry equipment and corrected according to the specifications. An anticracking net cover was installed around the test machine to ensure safety.

In the compressive strength test, loading rate was controlled between 0.08 and $0.10 \mathrm{MPa} / \mathrm{s}$. When the specimen was close to failure and began to deform sharply, we stopped adjusting the throttle of the testing machine until failure occurred. 


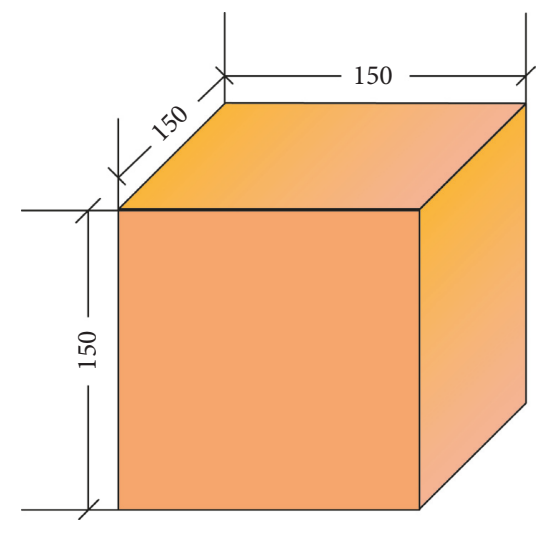

(a)

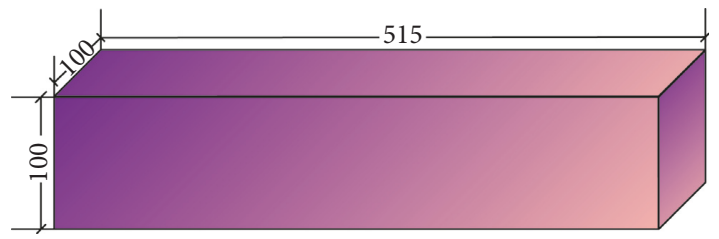

(b)
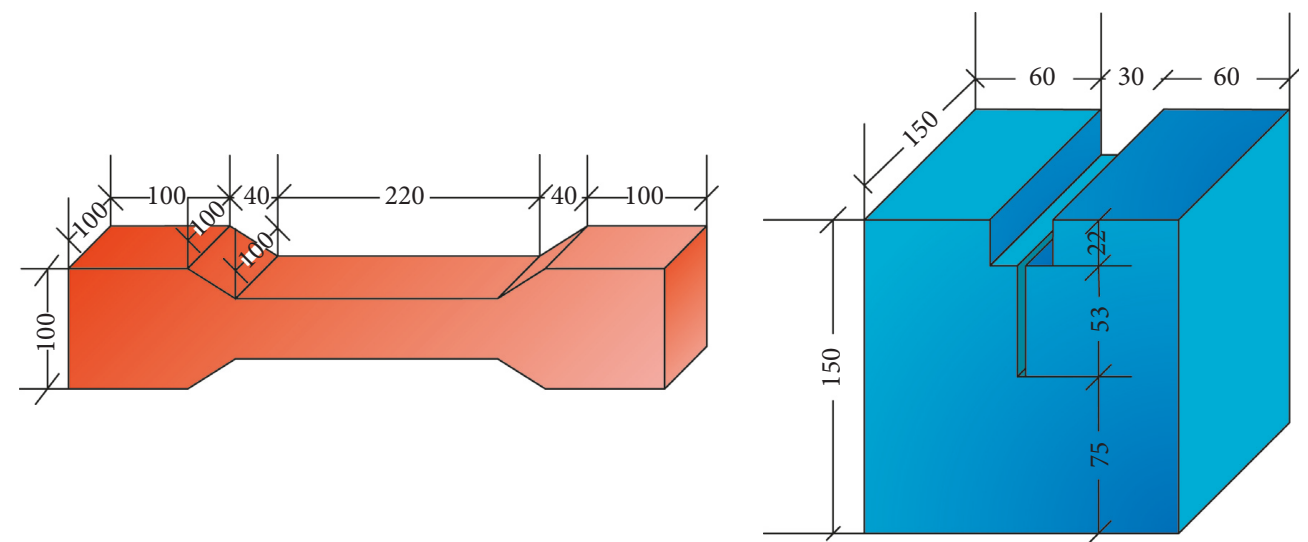

(d)

(c)

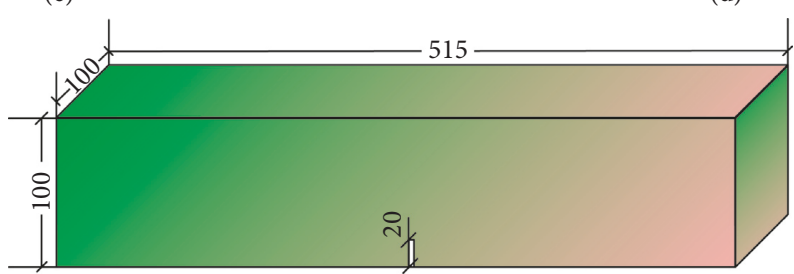

(e)

FIGURE 2: Shapes and sizes of specimens in different tests in millimetres: (a) compressive strength test specimen; (b) flexural strength test specimen; (c) uniaxial tensile test specimen; (d) wedged split tensile test specimen; (e) bending test specimen.

In the flexural strength test, the loading rate was controlled between 0.08 and $0.10 \mathrm{MPa} / \mathrm{s}$. Using the flexural test device, two equal loads were simultaneously applied at three points of the specimen span. The loading diagram is shown in Figure 3.

In the uniaxial tensile test, a pair of special fixtures (Figure 4) matching the size of the test specimen were used, and the loading rate was controlled at $1.2 \mathrm{~mm} / \mathrm{min}$. To reduce the effects of eccentric load, the articulated ring was welded to the outer end of the upper fixture and greased to improve articulation effects.

In the wedged split tensile test, the loading rate was controlled at $0.3 \mathrm{~mm} / \mathrm{min}$ using a step-by-step continuous loading method. The splitting and pulling device (Figure 5) was clamped into the wide slot cut in advance in to the specimen. The clamp extensometer was installed to monitor the $V$ value of the crack. The time from the beginning of loading to fracturing of specimens was $30-50 \mathrm{~min}$. When the specimen approached failure, the loading speed was reduced and the test process was maintained at as table level. Finally, the $F-V$ curve for the test was obtained.

In the bending test, a $20 \mathrm{~mm}$ crack was cut into the center of the lower surface for specimen. The loading speed was controlled at $0.025 \mathrm{~mm} / \mathrm{min}$, and a clamp extensometer was installed to monitor the crack deflection. When the material approached failure, the loading speed was reduced appropriately. Finally, the $F-\delta$ curve (load-deflection curve) for the three-point bending notched beam was obtained.

\section{Results and Discussion}

3.1. Compressive Strength Test. Vertical load was recorded using Test Master measurement and control software, and the peak values were labeled. The numerical values were accurate to $0.1 \mathrm{MPa}$. Normally, the average value of three specimens is taken as the strength value of the group of 


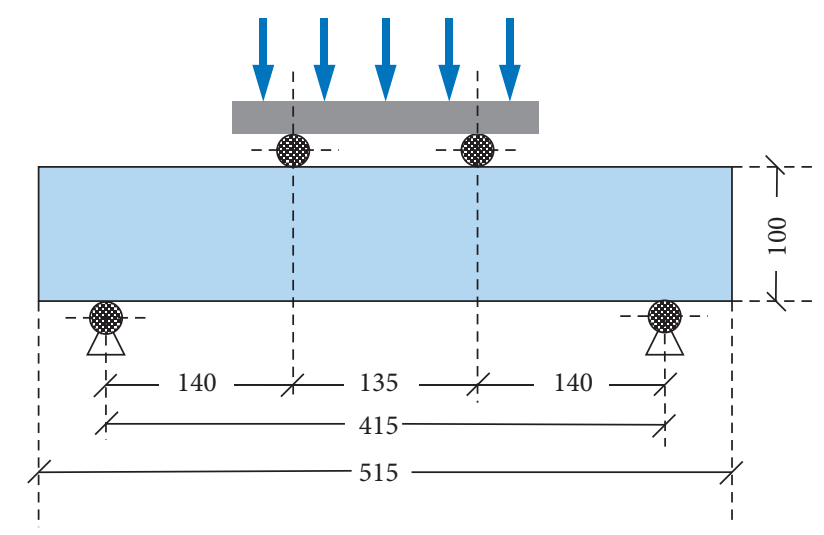

FIGURE 3: Specimen dimensions and loading manner of the flexural test.

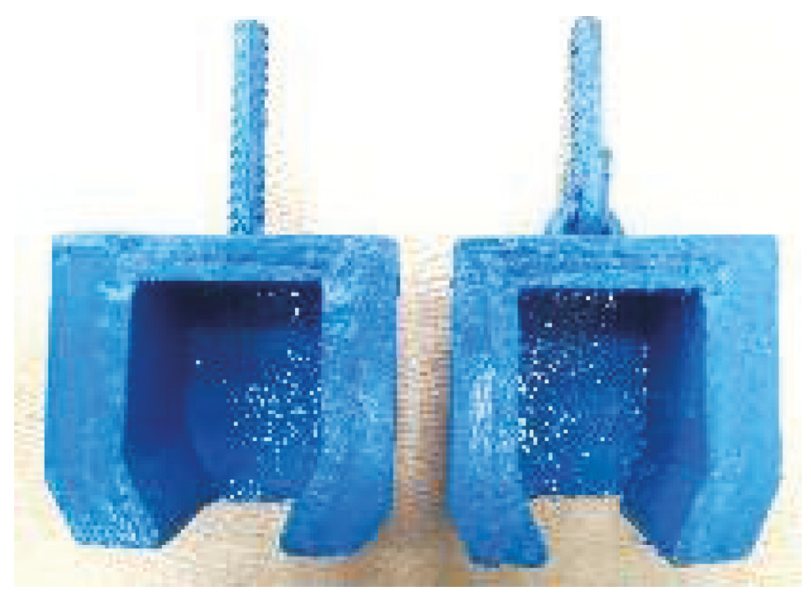

FIGURE 4: Special fixtures used in the uniaxial tensile test.

specimens. However, if the difference between the maximum value and the minimum value of the three measurements exceeds $15 \%$ of the median value, the maximum value and the minimum value are discarded, and the median value is taken as the compressive strength value of the group of specimens. If the difference between the maximum and the median value and the minimum and the median value exceeds $15 \%$ of the median values, the test results for the specimen group are invalid. The test results are listed in Table 3.

Table 3 shows that the compressive strength of PPMFRC increased with increasing fiber ratios. For fiber ratios of $1.0 \%$ and $1.5 \%$, the strength increased by $3.4 \%$. It shows that the addition of polypropylene macrofibers improves the compressive strength of concrete; however, the range is limited. The best volume ratio to improve the compressive strength of PPMFRC can be selected as $1.0 \%$.

3.2. Flexural Strength Test. Flexural strength was calculated from peak load. Because the specimen sizes were nonstandard, the flexural strength results had to be converted (formula 1). The numerical value was accurate to $0.1 \mathrm{MPa}$. The strength determination method was the same as that in

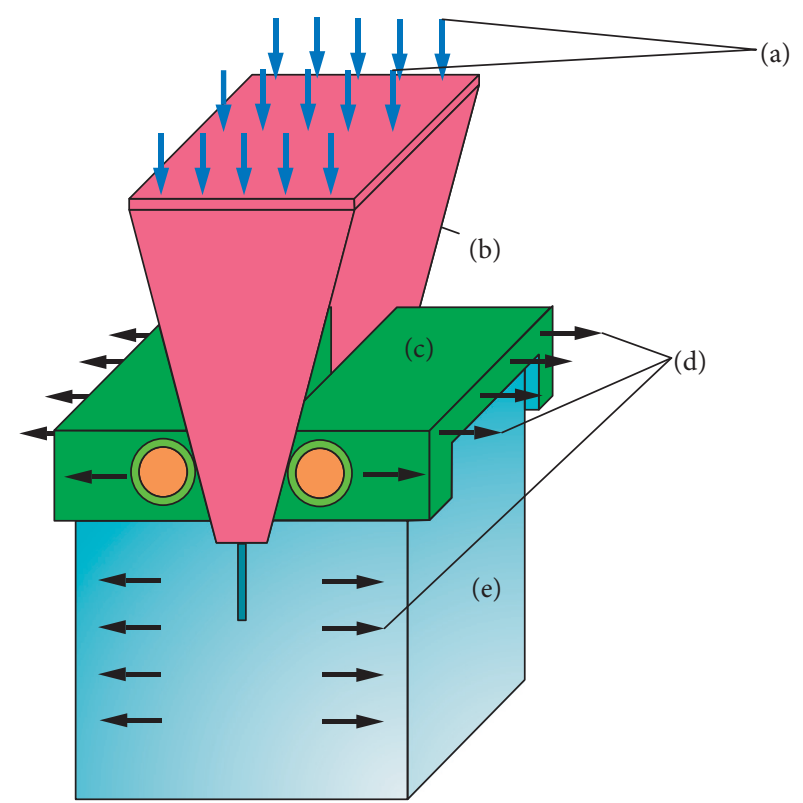

FIGURE 5: Loading manner of wedged split tensile test: (a) uniformly distributed load; (b) vertical pressure transfer device; (c) horizontal pressure transfer device; (d) displacement direction; (e) specimen.

compressive strength testing. The test results are listed in Table 4:

$$
f_{\mathrm{f}}=0.85 \frac{F_{z \max } l}{b h^{2}},
$$

where $f_{\mathrm{f}}$ is the flexural strength $(\mathrm{MPa}), 0.85$ is the dimension conversion coefficient, $F_{z \max }$ is the peak load $(\mathrm{kN}), l$ is the span between supports ( $\mathrm{mm}), h$ is the section height $(\mathrm{mm})$, and $b$ is the section weight $(\mathrm{mm})$.

Figure 6 shows that before the ultimate flexural strength of plain concrete was reached, the curves basically coincided and linearity was evident. Then, different curves began to show different trends. After reaching the peak value, the stress of plain concrete decreased rapidly. Although the concrete had residual strength, it was completely destroyed in a short time and brittle failure was very evident. Over time, PPMFRC materials with different fiber dosages continued to bear loads. PPMFRC reached its ultimate strength and was destroyed at $210 \mathrm{~s}$, which was nearly $30 \mathrm{~s}$ longer than the duration for plain concrete. Additionally, the decline rate of PPMFRC was slower than that of plain concrete. When the fiber content was $1.0 \%$, PPMFRC had the highest flexural strength. Therefore, $1.0 \%$ can be used as the best volume fraction for flexural strength.

3.3. Uniaxial Tensile Strength Test. We found that most of the fibers were pulled out of the material. Meanwhile, a few fibers were not pulled out; however, they were instead broken because of the strong bond between the fibers and the concrete matrix. When the concrete cracked, the bonding force between the fibers and the concrete matrix played a key role. Then, most of the fibers were pulled out. However, a few fibers having a high bonding force with the 
TABLE 3: Compressive strength test results.

\begin{tabular}{lcc}
\hline Group & Compressive strength $(\mathrm{MPa})$ & Increase range (\%) \\
\hline A-0 & 64.3 & 0 \\
A-0.5 & 66.2 & 3.0 \\
A-1.0 & 66.5 & 3.4 \\
A-1.5 & 66.5 & 3.4 \\
\hline
\end{tabular}

TABLE 4: Flexural strength test results.

\begin{tabular}{lcc}
\hline Group & Flexural strength $(\mathrm{MPa})$ & Increase range $(\%)$ \\
\hline A-0 & 5.8 & 0 \\
A-0.5 & 6.8 & 17.2 \\
A-1.0 & 7.5 & 29.3 \\
A-1.5 & 7.3 & 25.9 \\
\hline
\end{tabular}

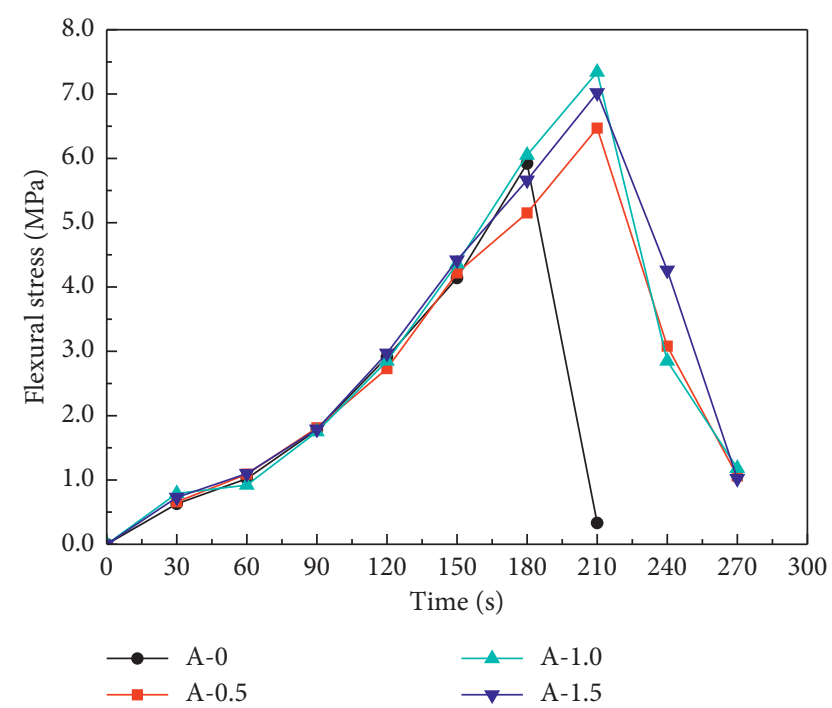

FIGURE 6: Relationship between flexural stress and time.

concrete matrix were not pulled out, and their tensile strength resisted overall fracturing.

Because of the randomness of the distribution of coarse aggregate and fibers in the concrete, the distribution of original defects such as cracks and voids in the concrete was also random (Figure 7). The internal randomness caused the strength and stress distributions to different in various sections of specimens; thus, no evident specimen failure was observed. The fracture surfaces for some specimens were near the middle of the specimens. However, the fracture surfaces for the other specimens were only approximately 110-140 $\mathrm{mm}$ away from the clamp opening.

During testing, a few specimens cracked on the one side, and then on the other side, the cracks eventually expand to the interior and break through. Most of the specimens cracked initially on one side, with the cracks gradually expanding to the interior and ultimately penetrating the damage. This phenomenon was mainly owing to a certain degree of eccentric tension after the first initial cracking in most specimens, which resulted in the crack extending inward along one side.

Table 5 shows that, with increase in fiber content, both the ultimate tensile strength and peak strain increased.

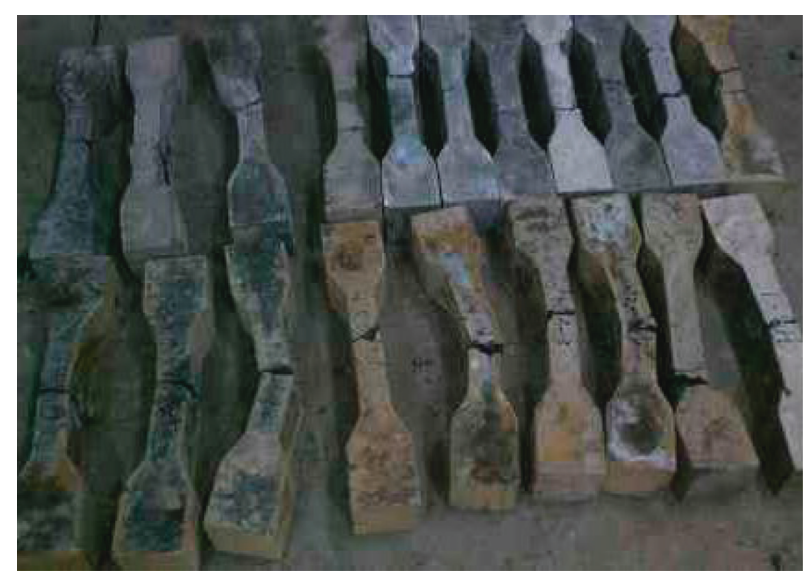

Figure 7: Fractured specimens after the uniaxial tensile test.

When the dosage was $1.5 \%$, the ultimate tensile strength was $21.4 \%$ higher than that of plain concrete. In the stage prior to the $70-80 \%$ peak values, the stress-strain relationship was linear elastic. In this stage, the microcracks were relatively smaller and their influence was weak. With increasing stress, microcracks gradually began to expand, which affected the stress area of the specimen, making residual stress increase and further increasing failure trends.

3.4. Wedged Split Tensile Test. Draw F-V curve (vertical loaddisplacement of crack opening curve) (Figure 8) and calculate initial fracture toughness $K_{\mathrm{IC}}^{\text {ini }}$, instability fracture toughness $K_{\mathrm{IC}}^{\mathrm{un}}$, effective crack length $a_{\mathrm{c}}$, fracture energy $G_{\mathrm{f}}$, and tensile strength $f$ :

$$
\begin{aligned}
K_{\mathrm{IC}}^{\mathrm{ini}} & =\frac{F_{\mathrm{HQ}} \times 10^{-3}}{t \sqrt{h}} f(\alpha), \\
K_{\mathrm{IC}}^{\mathrm{un}} & =\frac{F_{\mathrm{HS}} \times 10^{-3}}{t \sqrt{h}} f(\alpha), \\
a_{\mathrm{c}} & =\left(h+h_{0}\right)\left[1-\sqrt{\frac{13.18}{\left(t E V_{\mathrm{c}} / F_{\mathrm{HS}}\right)+0.16}}\right]-h_{0}, \\
G_{\mathrm{f}} & =\frac{W}{t h}, \\
f & =\frac{6 F_{\mathrm{ZS}} y}{t h^{2}}+\frac{F_{\mathrm{ZS}}}{t h},
\end{aligned}
$$

where $F_{\mathrm{HQ}}$ is the horizontal load of initial fracture $(\mathrm{kN}), F_{\mathrm{HS}}$ is the horizontal load of instability fracture $(\mathrm{kN}), t$ is the ligament thickness $(\mathrm{mm}), h$ is the ligament height $(\mathrm{mm}), h_{0}$ is the thickness of cutter edge thin steel plate of clamp extension meter $(\mathrm{mm}), a_{0}$ is the initial length of crack $(\mathrm{mm})$, $E$ is the modulus of elasticity $(\mathrm{GPa}), c_{i}=V_{i} / F_{i}$, is the reciprocal slope of straight line segment in curve ascent $(\mathrm{mm} /$ $\mathrm{kN}), \quad \alpha=\alpha_{\mathrm{c}} / h, f(\alpha)=3.675[1-0.12(\alpha-0.45)](1-\alpha)^{-3 / 2}$, $V_{\mathrm{c}}$ is the critical value of crack opening displacement $(\mathrm{mm})$, $W$ is the work done by vertical load, envelope area of $F-V$ curve $(\mathrm{J})$, and $y$ is the distance from the ligament center to the horizontal loading point $(\mathrm{mm})$ [10]. The test and calculation results are listed in Table 6. 
TABLE 5: Uniaxial tensile test results.

\begin{tabular}{lccc}
\hline Group & $\begin{array}{c}\text { Uniaxial tensile } \\
\text { strength }(\mathrm{MPa})\end{array}$ & $\begin{array}{c}\text { Increase } \\
\text { range }(\%)\end{array}$ & $\begin{array}{c}\text { Peak strain } \\
\left(\times 10^{-6}\right)\end{array}$ \\
\hline A-0 & 2.8 & 0 & 117.63 \\
A-0.5 & 3.1 & 10.7 & 124.63 \\
A-1.0 & 3.2 & 14.3 & 145.41 \\
A-1.5 & 3.4 & 21.4 & 152.34 \\
\hline
\end{tabular}

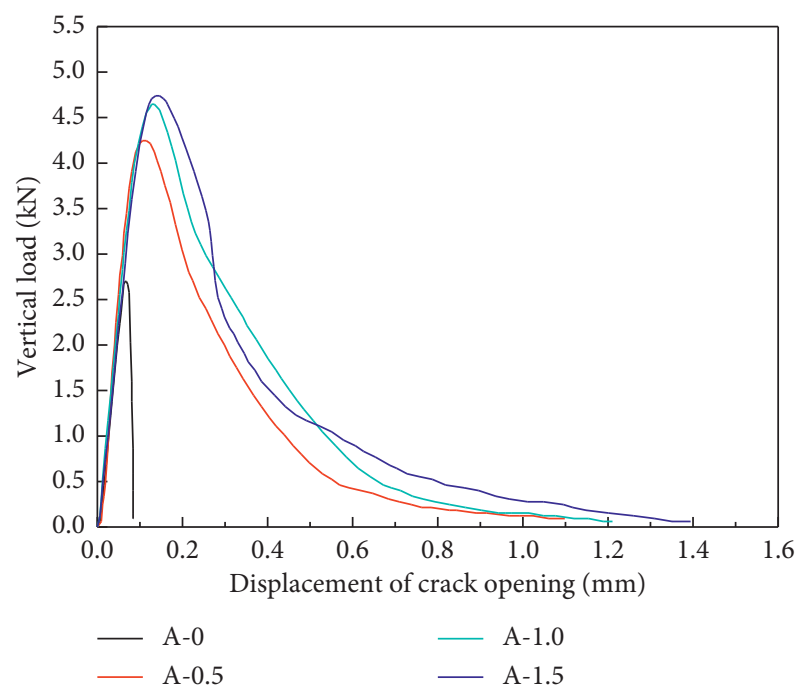

FIGURE 8: Relationship between vertical load and displacement of crack opening.

The failure modes of concrete can be clearly observed from Figure 9. The matrix of plain concrete is completely split and divided into two parts. The brittle failure mode is evident. Under the same stress, PPMFRC with $1.5 \%$ fiber content exhibits microcracks but no evident damage, and the effects of fiber crack prevention are evident.

3.5. Bending Test. According to the load, deflection, and crack opening displacement measured by the test, $F-\delta$ curve (vertical load-deflection) is drawn, and the fracture toughness $K_{\mathrm{IC}}$ and fracture energy $G_{\mathrm{f}}$ are calculated:

$$
\begin{aligned}
K_{\mathrm{IC}} & =\frac{6 Y M_{\max } \sqrt{a_{0}}}{t h^{2}}, \\
G_{\mathrm{f}} & =\frac{A_{0}+m_{\mathrm{g}} \delta_{\max }}{A_{\text {lig }}},
\end{aligned}
$$

where $Y(l / h)=1.93-3.07(l / h)+14.53(l / h)^{2}-25.11(l / h)^{3}+$ $25.8(l / h)^{4}$ is the shape factor, $M_{\max }$ is the sum of the maximum load and the bending moment produced by the deadweight of the beam $(\mathrm{N} / \mathrm{m}), a_{0}$ is the notch depth $(\mathrm{mm}), A_{0}$ is the envelope area of $F-\delta$ curve $\left(\mathrm{mm}^{2}\right), m_{\mathrm{g}}$ is the deadweight of support section of concrete beam $(\mathrm{kN})$, $\delta_{\max }$ is the deformation of beams at final failure $(\mathrm{mm})$, and $A_{\text {lig }}$ is the ligament area $\left(\mathrm{mm}^{2}\right)$. The meaning of other parameters is consistent with that of the penetration splitting test. The test and calculation results are listed in Table 7.

Figure 10 shows that there are only two stages in plain concrete: elastic and failure stages. The brittle failure characteristics are evident. PPMFRC has evident elasticplastic characteristics, which can be divided into the elastic, deflection stable development, deflection instability, and failure stages. In the elastic stage, the curve is linear and the fibers and concrete bear the load together. In the stable development stage of deflection, when the ultimate load reaches $70-80 \%$, the curve slows, the matrix cracks begin to propagate slowly, and the fibers across the cracks begin to play a role in delaying the crack propagation speed until it reaches a peak value. Macroscopic cracks begin to appear near the peak load. In the deflection instability stage, after reaching peak stress, the curve is steep, because the specimen reaches its ultimate strength and destructs. The bearing capacity decreases sharply; however, the deflection changes little. In the damage stage, the fibers show strong crack resistance, with little change in the bearing capacity of the specimens. The deflection continues to develop until the specimens are destroyed, reflecting the high toughness of PPMFRC.

With increasing fiber content, the ultimate strength loads and peak deflection increase. The fiber volume fraction has an evident effect on bending resistance, and fracture energy also increases. The value is between 382.7 and $485.6 \mathrm{~N} / \mathrm{m}$. This occurs mainly because the fibers connect the cracks and span between them. When the microcracks expand, the fibers effectively alleviate the stress concentrations of the cracks and prevent the cracks from expanding. The numerical results show that the fracture energy is significantly increased. In addition to overcoming the resistance of the concrete matrix itself, the external load also must overcome the bond stress between the fibers and the matrix, as well as the tensile strength of the fibers themselves.

\section{Conclusion}

(1) The flexural strength, tensile strength, fracture toughness, and fracture energy of PPMFRC were evidently higher than those of plain concrete. However, the compressive strength of PPMFRC was only slightly higher than that of plain concrete.

(2) For a fiber content of $1.0 \%$, the flexural strength of PPMFRC was $29.3 \%$ higher than that of plain concrete. With increase in fiber content, the uniaxial tensile strength and wedged split tensile strength of PPMFRC were improved. At a fiber content of $1.5 \%$, the uniaxial tensile strength was highest, and it was $21.4 \%$ higher than that of plain concrete.

(3) With increasing fiber content, the fracture energy of PPMFRC was improved. When the fiber content was $0.5-1.5 \%$, the fracture toughness of PPMFRC was $0.26-0.35$ and the fracture energy was $382.7-485.6 \mathrm{~N} /$ $\mathrm{m}$. Thus, the crack resistance of the PPMFRC is evidently better than that of plain concrete. 
TABLE 6: Wedged split tensile test results.

\begin{tabular}{lccccccc}
\hline Group & Wedged split tensile strength $(\mathrm{MPa})$ & Increase range $(\%)$ & $V_{\mathrm{c}}(\mu \mathrm{m})$ & $a_{\mathrm{c}}(\mu \mathrm{m})$ & $K_{\text {ini }}(\mathrm{MPa} / \sqrt{\mathrm{m}})$ & $K_{\mathrm{IC}}^{\mathrm{un}}(\mathrm{MPa} / \sqrt{\mathrm{m}})$ & $G_{\mathrm{f}}(\mathrm{N} / \mathrm{m})$ \\
\hline A-0 & 2.4 & 0 & 63.69 & 81.13 & 0.54 & 1.48 \\
A-0.5 & 3.4 & 41.7 & 84.51 & 112.25 & 0.61 & 89.06 \\
A-1.0 & 3.8 & 58.3 & 96.90 & 136.19 & 0.68 & 1.48 \\
A-1.5 & 3.9 & 62.5 & 122.65 & 167.08 & 0.70 & 1.61 & 153.89 \\
\hline
\end{tabular}

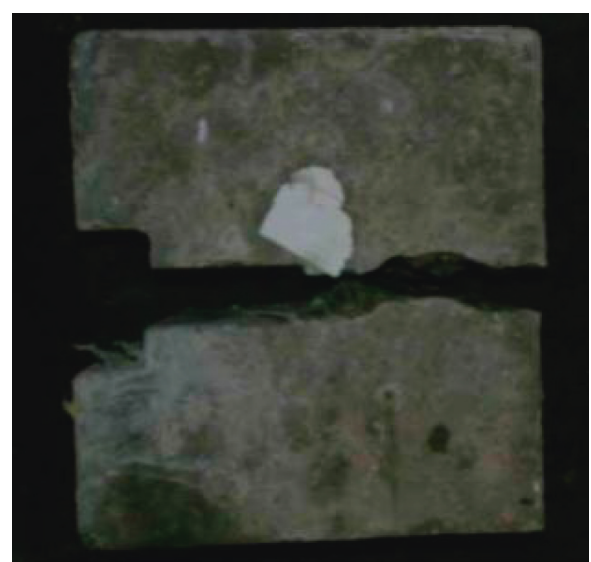

(a)

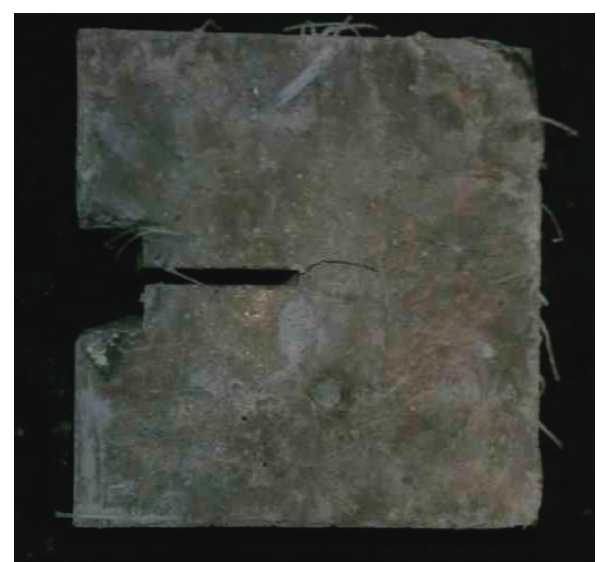

(b)

FIGURE 9: Specimens damaged by the wedged split tensile test: (a) plain concrete; (b) PPMFRC of 1.5\% polypropylene macrofibers content.

TABLE 7: Bending test results.

\begin{tabular}{lccccc}
\hline Group & Ultimate bearing load $(\mathrm{kN})$ & Increase range $(\%)$ & Peak deflection $(\mathrm{mm})$ & $K_{\mathrm{IC}}\left(\mathrm{MPa} / \mathrm{m}^{1 / 2}\right)$ & $G_{\mathrm{f}}(\mathrm{N} / \mathrm{m})$ \\
\hline A-0 & 10.0 & 0 & 0.1340 & 0.25 & 279.2 \\
A-0.5 & 10.6 & 6.0 & 0.2096 & 0.26 & 382.7 \\
A-1.0 & 12.4 & 24.0 & 0.3221 & 0.31 \\
A-1.5 & 14.0 & 40.0 & 0.6118 & 0.35 & 429.5 \\
\hline
\end{tabular}

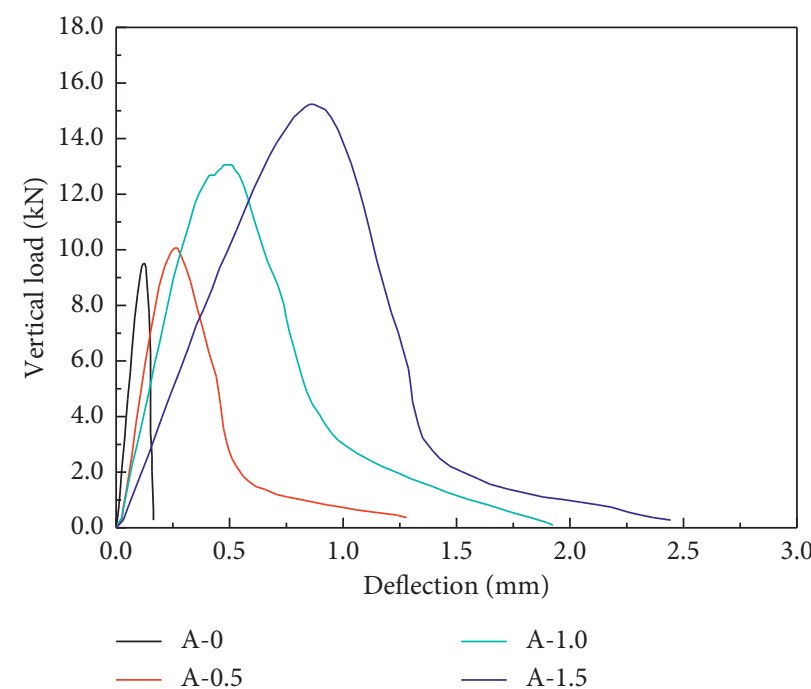

Figure 10: Relationship between vertical load and deflection. 
(4) Both the $F-V$ and $F-\delta$ curves exhibited the brittleness characteristics of plain concrete and the elasticplastic characteristics of PPMFRC, and they indicated the evident anticracking and toughening effects of the fibers.

\section{Data Availability}

The data used to support the findings of this study are included within the article.

\section{Conflicts of Interest}

The authors declare that they have no conflicts of interest.

\section{Acknowledgments}

This study was supported by the National Natural Science Foundation of China (no. 51674006), Anhui Province University Disciplines (Professional) Top-Notch TalentFunded Projects (gxbjZD09), Anhui Provincial Natural Science Foundation Youth Project (1908085QE185), Anhui Provincial College of Natural Science Research Key Project (KJ2018A0098), project funded by China Postdoctoral Science Foundation (2018M642502), and Science Research Foundation for Young Teachers in Anhui University of Science and Technology (QN2017211).

\section{References}

[1] Z. S. Yao, H. Cheng, and X. B. Ju, "Research and application of high strength steel fiber concrete compound shaft lining with inner steel plate in deep alluvium shaft repair," Journal of China Coal Society, vol. 42, no. 9, pp. 2295-2301, 2007.

[2] T. Han, W. H. Yang, Y. L. Ren, and Z. J. Yang, "Numerical and experimental model studies of the horizontal bearing properties of shaft lining of encased steel or steel fiber reinforced, high strength concrete," Journal of China University of Mining \& Technology, vol. 41, no. 2, pp. 205-211, 2012.

[3] M. S. Wei, L. S. Li, Q. P. Zheng, and Q. A. Ding, "Comparative study of evaluate method for toughness factor of steel fiber reinforced concrete (SFRC)," Building Structure, vol. 37, no. 12, pp. 90-92, 2007.

[4] S. Z. Qi and W. H. Yang, "Study of mechanical characteristics of high strength steel fiber reinforced concrete shaft lining with inner steel plate," Coal Engineering, vol. 48, no. 3, pp. 103-106, 2016.

[5] Y.-z. Bi, D.-l. Zhang, and J.-h. Hu, "Application of modified polypropylene (crude) fibers concrete to strengthen the support structures in deep mine roadway," Journal of Coal Science and Engineering (China), vol. 18, no. 4, pp. 379-384, 2012.

[6] Z. Z. Sun and Q. W. Xu, "Microscopic, physical and mechanical analysis of polypropylene fiber reinforced concrete," Materials Science and Engineering, vol. 527, no. 1-2, pp. 198-204, 2009.

[7] A. A. Ramezanianpour, M. Esmaeili, S. A. Ghahari, and M. H. Najafi, "Laboratory study on the effect of polypropylene fiber on durability, and physical and mechanical characteristic of concrete for application in sleepers," Construction and Building Materials, vol. 44, pp. 411-418, 2013.
[8] China Standards Publication, Standard for Test Method of Mechanical Properties or Plain Concrete, GB/T50081-2002, Standard Press of China, Beijing, China, 2002.

[9] China Standards Publication, Technical Specification for Application of Fiber Reinforced Concrete, JG/T 221-2010, Standard Press of China, Beijing, China, 2010.

[10] S. L. Xu, "The calculation approaches of double-K fracture parameters of concrete and a possible coding standard test method for determine them," Journal of China Three Gorges University (Natural Sciences), vol. 24, no. 1, pp. 1-8, 2002. 


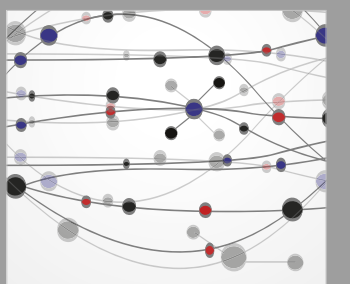

The Scientific World Journal
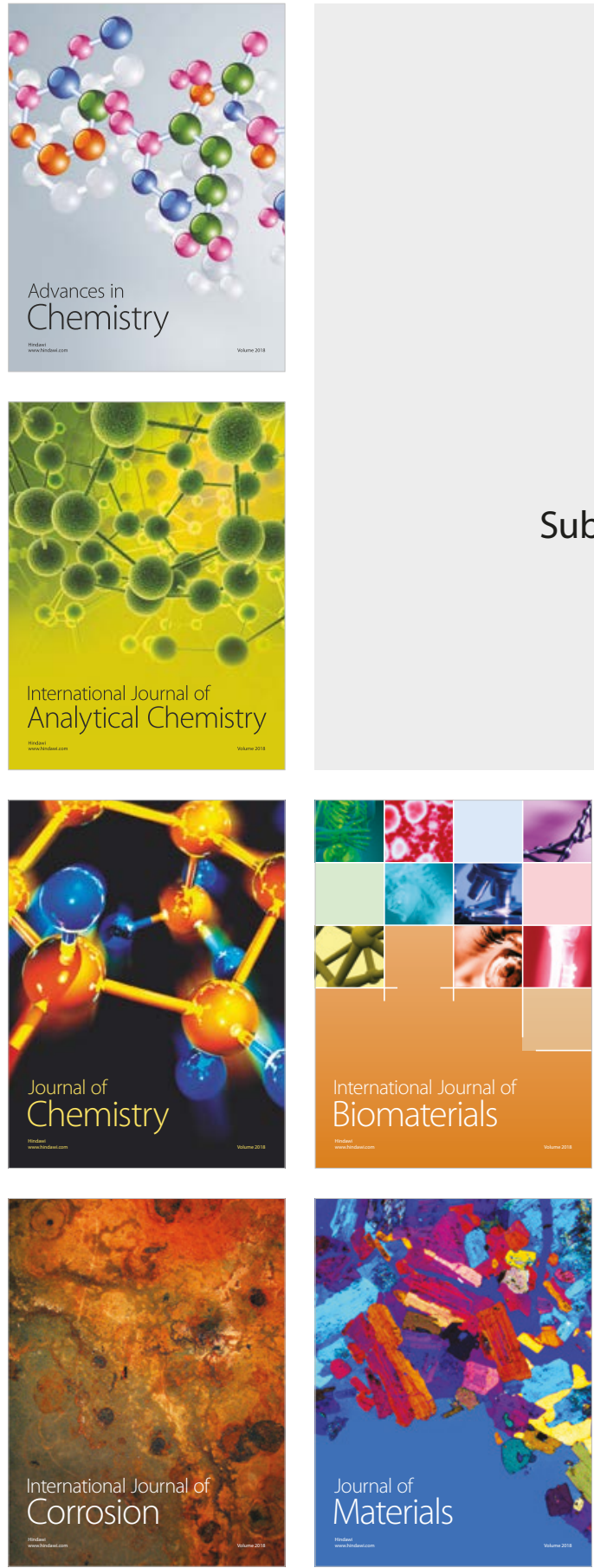

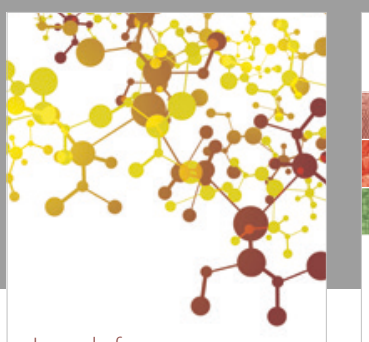

Journal of

Applied Chemistry
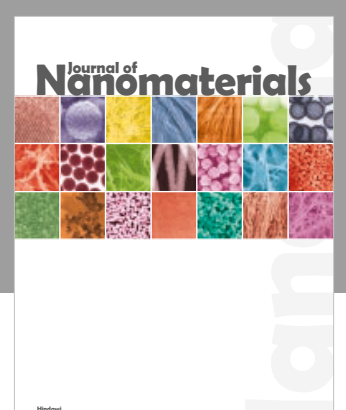

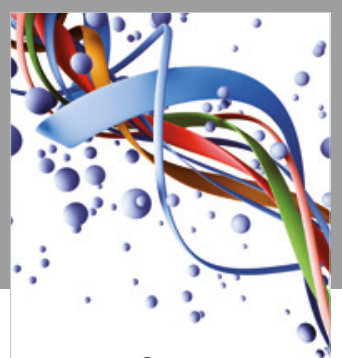

Scientifica

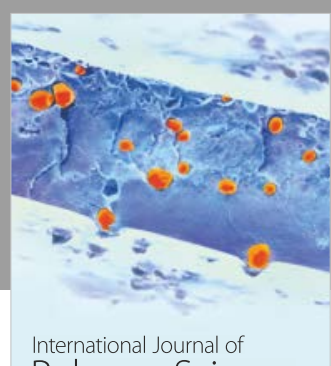

Polymer Science

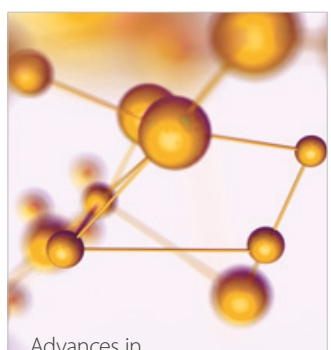

Physical Chemistry
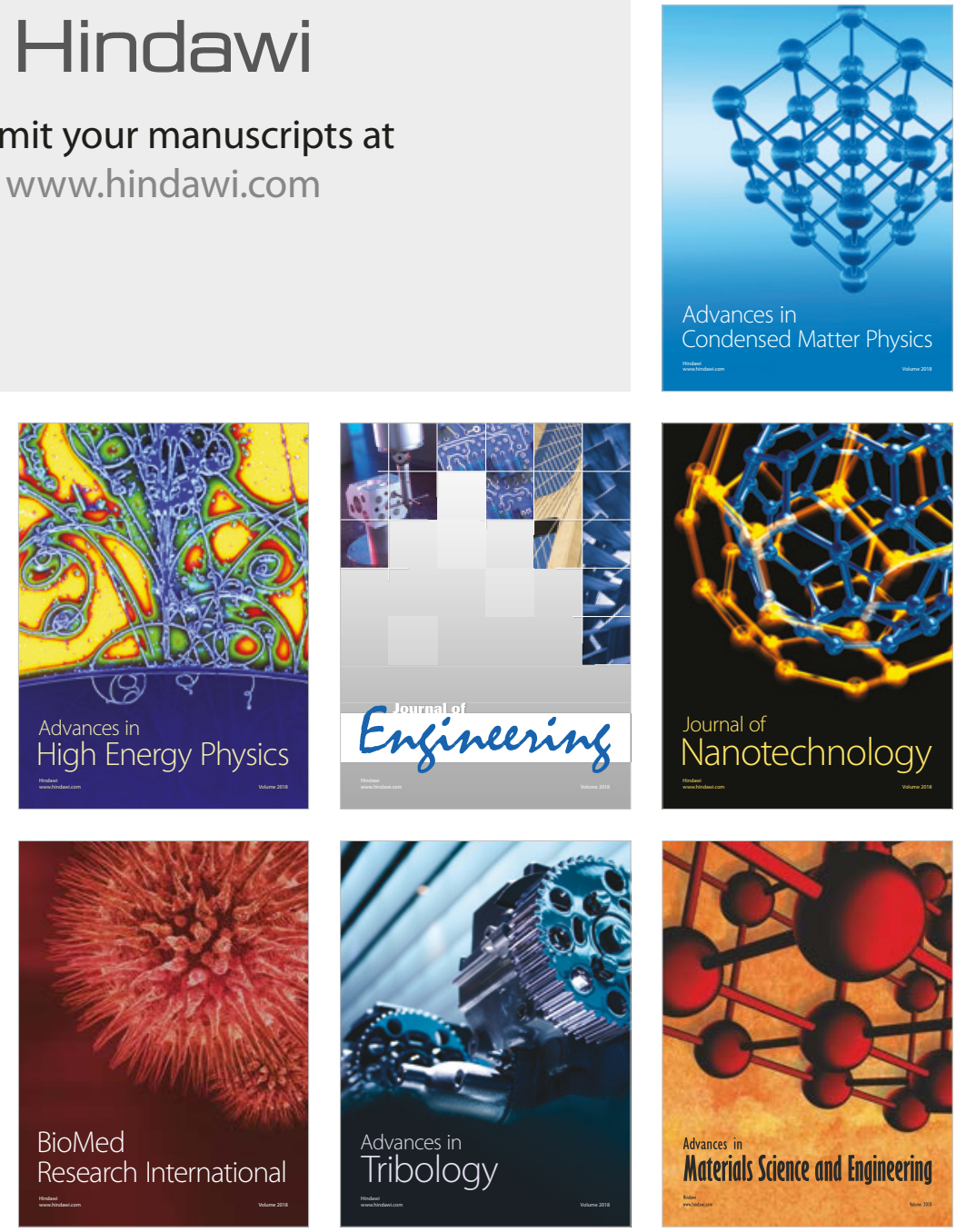